\title{
ЭкСпертизд
}

ЮДИНА Вера Александровна - кандидат экономических наук, доцент; заведующий кафедрой менеджмента, информатики и общегуманитарных наук Пензенского филиала Финансового университета при Правительстве РФ (440052, Россия, г. Пенза, ул. Калинина, 33б; vaуиdina@fa.ru)

НАЗАРОВА Наталья Александровна - кандидат экономических наук, доцент департамента политологии факультета социальных наук и массовых коммуникаций Финансового университета при Правительстве РФ (125993, Россия, г. Москва, ГСП-3, Ленинградский пр-кт, 49; паanazarova@fa.ru) ЮРАСОВ Игорь Алексеевич - доктор социологических наук, доцент; профессор кафедры менеджмента, информатики и общегуманитарных наук Пензенского филиала Финансового университета при Правительстве РФ (440052, Россия, г. Пенза, ул. Калинина, 33б; jurassow@таil.ru)

\section{ПОЛИТИЧЕСКАЯ АКТИВНОСТЬ НАСЕЛЕНИЯ ПРОВИНЦИАЛЬНОГО ГОРОДА В СЕТЕВОМ ИНФОРМАЦИОННОМ ПРОСТРАНСТВЕ}

\begin{abstract}
Аннотация. В статье рассматривается политическая активность населения в Интернете на примере исследования протестной активности в 24 провинциальных городах России. Авторы выявляют темы, вызывающие наибольший интерес в социальных сетях и онлайн-СМИ, репрезентативные и актуальные интернет-источники информации для населения и делают выводы о локальности и ситуационности информационных интересов, низком уровне протестного потенциала и владения работой с онлайн-ресурсами. Ключевые слова: политическое участие, протестная активность, сетевое пространство, политические коммуникации
\end{abstract}

Подходы к исследованию. Ускорение цифровизации всех сфер жизни населения (по итогам 2020 г.) приводит к возрастанию актуальности исследований, направленных на изучение интернет-активности как развивающейся формы политического участия граждан. Под влиянием цифровых коммуникаций происходит трансформация гражданской активности.

Обрашаясь к этой теме, в первую очередь необходимо указать на широкую международную дискуссию о степени влияния Интернета на уровень политической вовлеченности населения, особенно молодого поколения, а также о формирующихся новых типах и моделях политического и гражданского участия. Так, в статье Р.В. Пырмы данная дискуссия представлена с позиций кибероптимистов и пессимистов, где пессимисты в большей степени рассматривают негативные последствия, такие как разобщенность граждан, ведущая к снижению политической активности, а кибероптимисты подчеркивают расширение доступа к информации, увеличение возможностей и форм мобилизации, появление новых форматов участия, преобразующихся в политические действия [Пырма 2019: 69].

В статьях Э.И. Авзаловой и А.М. Ваховского на основе предложенной еще в 60-е гг. XX в. У. Милбрайтом классификации формы политического участия с точки зрения реализации в интернет-пространстве анализируются конвенциональные (интернет-голосование, петиции, информация о политических акциях, митингах, виртуальные съезды партии и др.) и неконвенциональные (политические провокации, хакерские атаки и др.) формы политического участия. Авторы статей видят потенциал интернет-пространства в улучшении взаимодействия между государством и обществом, привлечении граждан к решению политических проблем и задач повседневной политики, таким образом рассматривая интернет-активность как новый тип политического участия [Авзалова 2015: 188; Ваховский 2016: 13]. 
При этом авторы исследований, касающихся влияния цифровизации на гражданскую и политическую активность молодежи, обращают внимание, что в настоящий момент фиксируется быстрый переход гражданского участия молодых людей в политическое, онлайн-активностей - в офлайн, конвенциональных форм - в неконвенциональные [Бродовская, Пырма, Домбровская 2020: 46].

Также исследователи отмечают новые коммуникативные стратегии активистов в Интернете, преследующие политические цели [Каминская, Помигуев, Назарова 2019: 383], такие как сторителлинг, визуализация контента, технологическая активизация сопричастности целевой аудитории и коммуникативное лидерство (своевременная реакция на политическую повестку и активизация политического дискурса).

Обращаясь к теме протестной активности в Интернете, можно заметить полярность взглядов, похожую по смыслам на дискуссию, описанную выше. С одной стороны, озвучивается позиция, что Интернет является ключевым источником массовых протестных движений [Castells 2012; Howard, Muzammil 2013], с другой - выражается скептическое отношение к данной его роли [Rodgers 2003; Sunstain 2007; Woolley, Limperos, Oliver 2011].

В исследовании С.Г. Ушкина выделяются пять основных теоретико-методологических подходов к сетевой протестной активности: теории «умной толпы», минимизации затрат, сетей и потоков, солидаризации и социального перфоманса, слактивизма. Автор отмечает, что в каждом описанном направлении социальные сети являются эффективным ресурсом, минимизирующим финансовые, эмоциональные и временные затраты независимо от характера их влияния - позитивного или негативного [Ушкин 2015: 12].

Отдельно можно выделить исследование А.С. Ахременко, Д.К.Стукала и А.П. Петрова, выявившее, что показатели сетевой позиции автора в социальных сетях (число подписчиков, число подписчиков у пользователей, которые сделали репост, и др.) оказывают большее влияние на формирование протестного настроения, чем содержание текста [Ахременко, Стукал, Петров 2020: 89].

В процессе исследования авторы статьи также опирались на теорию М. Кастельса, акцентирующую роль сетевого взаимодействия в формировании массового сознания. При этом характер данного взаимодействия связан с дифференциацией центров информационных потоков с меняющимся во времени уровнем влияния [Castells 2010].

Результаты исследования. Исследование проблем протестной активности в сетевом информационном пространстве было проведено в 2020 г. в 24 городах России. В выборочную совокупность вошли 1610 респондентов, из них 56,9\% - женщины и 43,1\% - мужчины разной возрастной категории и уровня образования.

В результате исследования было выявлено, что наибольший интерес в социальных сетях и онлайн-СМИ в последние 2-3 года вызывают темы, посвященные решению социальных проблем местных жителей, вопросам защиты прав человека, меньшинств и др. При этом темы, связанные с поддержкой политических партий, кандидатов, проведением акций, участием в волонтерской деятельности и защитой экономических интересов, вызывают наименьший интерес.

В качестве наиболее репрезентативных и актуальных источников информации большинство респондентов отметили онлайн-сообщества, подписчики которых активно обсуждают острые политические темы $(25,1 \%)$, официальные политические ресурсы органов государственной власти $(16,6 \%)$, а также политические ресурсы оппозиционных политических сил $(14,1 \%)$. К сожалению, 
$39,6 \%$ опрошенных не интересуются политическими проблемами и не используют в качестве источников информации сетевое информационное пространство.

Необходимо отметить достаточно низкий уровень политической активности респондентов и выражения политического протеста. Отвечая на вопрос: «Что из нижеперечисленного лично Вы делали в реальной жизни?» - большинство респондентов отмечают, что голосовали на выборах $(40,8 \%)$ и участвовали в подписании обращений, петиций $(24,4 \%)$. Участниками собраний и акций протеста были 5,4\% респондентов (см. рис. 1 ).

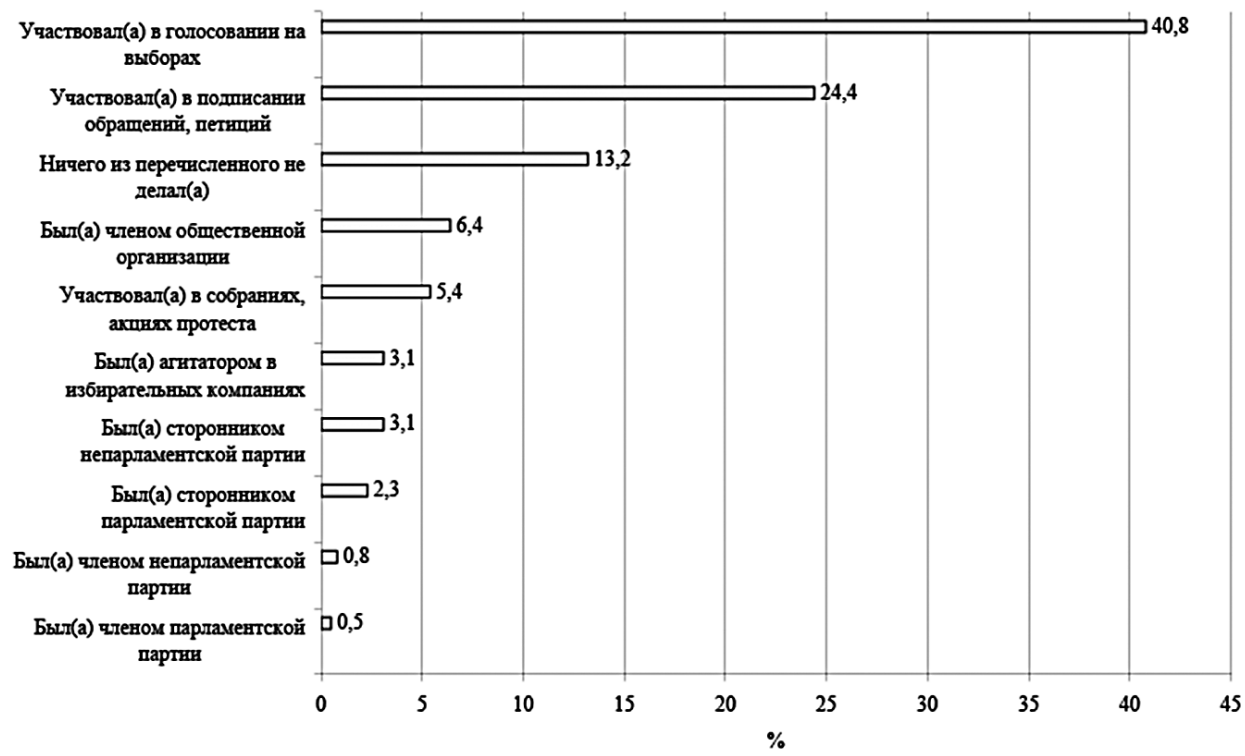

Рисунок 1. Распределение ответов респондентов на вопрос: «Что из нижеперечисленного лично Вы делали в реальной жизни?», \%

Современные онлайн-ресурсы часто содержат информацию, призывающую к участию в акциях политического и/или гражданского протеста. С подобного рода сообщениями сталкивались в общей сложности $61,4 \%$ респондентов. Респонденты, которые сталкивались с сообщениями, призывающими к участию в акциях политического и/или гражданского протеста, отмечают, что данные сообщения были посвящены несправедливым решениям власти $(17,3 \%)$, борьбе с коррупцией $(14,8 \%)$, ущемлению прав граждан $(14,1 \%)$, нарушениям при организации и проведении выборов $(11,3 \%)$, ущемлению прав меньшинств $(9,7 \%)$, ограничению интернет-прав $(7,3 \%)$, защите экономических интересов (обманутые дольщики) (6\%) и защите прав коренного населения $(4,4 \%)$. Среди своих вариантов ответа - «экология», «акции против поправок в Конституцию».

Можно отметить неоднозначность реакции респондентов на сообщения, призывающие к участию в акциях политического и/или гражданского протеста. Большинство опрошенных либо прочитывают данные сообщения, внимательно знакомятся с ситуацией $(35,8 \%)$, либо пропускают и не вчитываются в детали $(28,5 \%)$. Однако есть респонденты, которые после прочтения данных сообщений ищут единомышленников в своем кругу $(2,8 \%)$, обязательно при- 
нимают участие в акциях протеста $(1,2 \%)$ и связываются с организаторами, интересуются, чем могут быть полезны $(0,8 \%)$.

Наиболее информированы респонденты о таких лидерах оппозиции, как Ксения Собчак $(90 \%)$ и Алексей Навальный $(88,1 \%)$, наименее информированы о Евгении Альбац $(12,4 \%)$ и Владимире Кара-Мурзе мл. $(13,8 \%)$.

Уровень поддержки лидеров оппозиции достаточно низкий. Наибольшей поддержкой среди респондентов пользуется Алексей Навальный (37\%), наименьшей - Николай Сванидзе $(7,1 \%)$ и Леонид Гозман $(7,7 \%)$. Несмотря на то что Ксения Собчак наиболее известна среди респондентов (90\%), ее поддерживают лишь $13,1 \%$ опрошенных.

Таблица 1

Распределение ответов респондентов на вопрос: «Знаете ли и поддерживаете ли Вы следующих лидеров оппозиции?», \%

\begin{tabular}{|l|c|c|c|c|}
\hline \multirow{2}{*}{} & \multicolumn{2}{|c|}{$\begin{array}{c}\text { Уровень } \\
\text { информированности }\end{array}$} & \multicolumn{2}{|c|}{$\begin{array}{c}\text { Уровень } \\
\text { поддерки }\end{array}$} \\
\cline { 2 - 5 } & Знаю & Не знаю & Поддерживаю & Не поддерживаю \\
\hline 1. Алексей Навальный & 88,1 & 11,9 & 37 & 63 \\
\hline 2. Геннадий Гудков & 33,5 & 66,5 & 13,7 & 86,3 \\
\hline 3. Гарри Каспаров & 41,4 & 58,6 & 10,7 & 89,3 \\
\hline 4. Евгения Альбац & 12,4 & 87,6 & 10,3 & 89,7 \\
\hline 5. Илья Яшин & 32 & 68 & 12,8 & 87,2 \\
\hline 6. Виктор Шендерович & 18,4 & 81,6 & 8,7 & 91,3 \\
\hline 7. Александр Невзоров & 45,4 & 54,6 & 13,4 & 86,6 \\
\hline 8. Лев Пономарев & 21,5 & 78,5 & 10,4 & 89,6 \\
\hline 9. Михаил Касьянов & 38,3 & 61,7 & 9,1 & 90,9 \\
\hline 10. Михаил Ходорковский & 54,7 & 45,3 & 11,1 & 88,9 \\
\hline 11. Борис Вишневский & 31,3 & 68,7 & 9,2 & 90,8 \\
\hline 12. Владимир Кара-Мурза мл. & 13,8 & 86,2 & 9,2 & 90,8 \\
\hline 13. Дмитрий Гудков & 35,9 & 64,1 & 10,6 & 89,4 \\
\hline 14. Ксения Собчак & 90 & 10 & 13,1 & 86,9 \\
\hline 15. Леонид Гозман & 28,8 & 71,2 & 7,7 & 92,3 \\
\hline 16. Ольга Романова & 18,8 & 81,2 & 8,8 & 91,2 \\
\hline 17. Николай Сванидзе & 31,2 & 68,8 & 7,1 & 92,9 \\
\hline 18. Другое & - & - & - & - \\
\hline
\end{tabular}

Примечательно, что только 9,1\% респондентов могут назвать протестных лидеров своего региона.

Большинство респондентов $(91,3 \%)$ не посещают закрытые и заблокированные интернет-порталы протестной тематики. Лишь 5\% опрошенных их посещают. При этом уровень доверия к информации, представленной на этих порталах, находится на низком уровне. Только 3,9\% респондентов полностью доверяют данной информации.

Большинство респондентов $(86,9 \%)$ не посещают закрытые телеграммканалы протестной тематики, при этом уровень доверия к информации, пред- 
ставленной на этих каналах, находится на низком уровне. Только 4,6\% респондентов полностью доверяют данной информации.

В результате проведенного эмпирического исследования была выявлена специфика модели политической активности в сетевом информационном пространстве провинциальных городов России.

Особенностями данной модели являются: искажение местного экономического интереса, слабая сформированность социальных связей городского пространства, сочетание диаметрально противоположных проявлений политической активности населения, социально-психологическая специфика лидеров цифрового протеста, привязанная к региональным условиям, временная солидаризация политической активности населения в цифровом и реальном социальном пространстве с политическими оппозиционными силами в регионе.

Основные выводы. Таким образом, изучение политической активности населения провинциальных городов в сетевом информационном пространстве позволило выявить следующие основные тенденции:

- локальность и ситуационность информационных интересов, сосредоточенных вокруг региональных социально-экономических и экологических проблем, последствий пандемии;

- низкий уровень протестного потенциала, обусловленный политической неграмотностью;

- низкий уровень владения работой с онлайн-ресурсами, незнание концептов сетевой формы взаимодействия при формировании политического поведения и т.д.

Сетевое протестное поведение жителей провинциального города является одним из важнейших факторов трансформации политических региональных систем. Результаты мониторинга политической активности в сетевом информационном пространстве необходимы для оценки легитимности существующей власти, определения наиболее напряженных социально-экономических и политических проблем. На их основе должны разрабатываться рекомендации по управлению цифровой политической активностью населения жителей провинциального города Российской Федерации и возможные сценарии протестного поведения.

Исследование выполнено при финансовой поддержке РФФИ и ЭИСИ в рамках научного проекта № 20-011-31060 «Протестная активность в сетевом информационном пространстве провинциального города: дискурс, структура, иенности».

\section{Список литературы}

Авзалова Э.И. 2015. Интернет-участие как новая форма политического участия граждан. - Ученые записки Казанского университета. Сер. Гуманитарные науки. № 1. С. 187-193.

Ахременко А.С., Стукал Д.К., Петров А.П. 2020. Сеть или текст? Факторы распространения протеста в социальных медиа: теория и анализ данных. Полис. Политические исследования. № 2. С. 73-91.

Бродовская Е.В., Пырма Р.В., Домбровская А.Ю. 2020. Гражданский активизм молодежи России: структура ролей, факторы формирования установок, триггеры роста протестного потенциала. - Гуманитарные науки. Вестник Финансового университета. Т. 10. № 6. С. 39-49.

Ваховский А.М. 2016. Интернет-пространство: эволюция форм политического участия. - Известия ТулГУ. Гуманитарные науки. № 4. С. 13-21. 
Каминская Т.Л., Помигуев И.А., Назарова Н.А. 2019. Экологический активизм в цифровой среде как инструмент влияния на государственные решения. - Мониторинг общественного мнения: экономические и социальные перемены. № 5. C. 382-407.

Пырма Р.В. 2019. Влияние цифровых коммуникаций на политическое участие. - Гуманитарные науки. Вестник Финансового университета. № 9(4). C. 63-69.

Ушкин С.Г. 2015. Теоретико-методологические подходы к изучению сетевой протестной активности: от «умной толпы» к слактивизму. - Мониторинг общественного мнения: экономические и социальные перемены. № 3(127). С. 3-12.

Castells M. 2010. The Power of Identity: The Information Age: Economy, Society and Culture. Vol. II. Wiley-Blackwell. 538 p.

Castells M. 2012. Networks of Outrage and Hope. Social Movements in the Internet Age. Cambridge: Polity Press. Xiv, 300 p.

Howard P., Muzammil H. 2013. Democracy's Fourth Wave?: Digital Media and the Arab Spring. Oxford: Oxford University Press. 160 p.

Rodgers J. 2003. Spatializing International Politics. Analysing Activism on the Internet. London: Routledge. $184 \mathrm{p}$.

Sunstein C. 2007. Republic.com 2.0. New Jersey: Princeton University Press. Xiii, $251 \mathrm{p}$.

Woolley J., Limperos A., Oliver M. 2011. The 2008 Presidential Election, 2.0: A Content Analysis of UserGenerated Political Facebook Groups - New Media, Campaigning and the 2008 Facebook Election (ed. by T.J. Johnson, D.D. Perlmutter). Oxon, New York: Routledge. P. 79-100.

YUDINA Vera Aleksandrovna, Cand.Sci. (Ec.), Associate Professor; Head of the Chair of Management, Informatics and Human Sciences, Penza Branch of the Financial University under the Government of the Russian Federation (33B Kalinina St, Penza, Russia, 440052; vayudina@fa.ru)

NAZAROVA Natal'ya Aleksandrovna, Cand.Sci. (Ec.), Associate Professor of the Department of Political Science, Faculty of Social Sciences and Mass Communications, Financial University under the Government of the Russian Federation (49 Leningradsky Ave, GSP-3, Moscow, Russia, 125993; naanazarova@fa.ru)

YURASOV Igor' Alekseevich, Dr Sci. (Soc.), Associate Professor; Professor of the Chair of Management, Informatics and Human Sciences, Penza Branch of the Financial University under the Government of the Russian Federation (33B Kalinina St, Penza, Russia,440052; jurassow@mail.ru)

\section{STUDY OF POLITICAL ACTIVITY OF THE POPULATION OF PROVINCIAL CITY IN THE NETWORK INFORMATION SPACE}

\footnotetext{
Abstract. The article examines political activity of the population on the Internet using a study of protest activity in 24 provincial cities of Russia. The authors identify the topics of greatest interest in social networks and online media, representative and relevant Internet sources of information for the population and deduce the locality and situationality of information interests, as well as the low level of protest potential and the ability to work with online resources.

Keywords: political participation, protest activity, network space, political communications
} 